\title{
Towards a Novel Living Lab Model for Sustainable Innovation in the Construction Industry
}

\author{
David Romero ${ }^{1}$, Myrna Flores ${ }^{2}$, Carlos Vallejo ${ }^{1}$, Arturo Molina ${ }^{1}$ \\ ${ }^{1}$ CIDYT - ITESM Campus Monterrey \& Mexico City, Mexico \\ david.romero.diaz@gmail.com,calos.vallejo.b@gmail.com,armolina@itesm.mx \\ ${ }^{2}$ CEMEX Research Group AG, Global Center for Technology \& Innovation, Biel, Switzerland \\ myrnafatima.flores@cemex.com
}

\begin{abstract}
According to the United Nations Environment Programme, the construction industry is a key sector to achieve sustainable development, as it can provide important benefits in the complete construction lifecycle considering its three axes: social, economic and environmental. At the same time, negative impacts can be drastically reduced if new collaborative business models and strategies are defined integrating both end-users and different actors in the construction value-chain. Therefore, this paper introduces a general overview of a collaborative research project carried out by ITESM and CEMEX to develop and deploy a novel Sustainable Construction Living Lab (SCLL) model to bring together key construction stakeholders into an open innovation and user-centric environment, supported by a high-tech platform, providing working principles, methods and a governance model to identify next generation construction innovations (e.g. products, services, processes, business models, etc.) in order to satisfy the current and emerging market demands in a sustainable way.
\end{abstract}

\section{Keywords}

Construction Sector/Industry, Living Lab, Product-Process-Organisational Innovation, Sustainable Innovation

\section{Introduction}

The construction industry is undergoing an important evolution as emerging technologies and environmental concerns are changing how the construction industry does business, creating a considerable impact on its products, processes and value-chain structure. At the same time, governmental regulations are demanding more sustainable constructions, while customers are requesting intelligent buildings that permit a greater flexibility in use and energy efficiency, both issues leading the construction industry research to develop alternative materials, novel designs, and new construction systems and techniques. Additionally, global competitive forces are enabling new contractual agreements integrating more the construction industry stakeholders, blurring the boundaries in the value-chain between architects, designers, contractors, builders, suppliers and service providers, and giving birth to highly integrated construction enterprises [Paevere \& MacKenzie, 2007]. At the same time, undergoing industry collaborative projects in the sector, such as the Energy Efficiency Buildings (EEB) project proposed and currently managed by the World Business Council for Sustainable Development [http://www.wbcsd.org/] have identified other trends such as: (1) the need for a holistic design approach, integrating the complete construction community and end-users, (2) the right financial mechanisms and relationships in the development, operation and use of buildings and (3) behavioural changes as part of a wider social development by professionals and business users.

As a result, these latter trends are provoking a new wave of innovations in the construction industry, where besides the need for cost effective and novel products, processes and organisational structures, also ecological and social dimensions are also taken into consideration during their development and deployment. Sustainable Construction Innovation means creating new ways of reducing the energy requirements of buildings and reducing the environmental impact of structures during their entire lifecycle: planning, designing, building, using, 
maintaining and renewing or recycling. This includes product innovation in the use of new recycled/renewable materials; process innovation in resource-efficient construction methods minimizing materials, energy and wastes during structures erection; and organisational innovation in new collaborative models leading to higher levels of integration in the construction value-chain [Miozzo \& Dewick, 2004].

This paper will highlight the most important drivers in the construction industry that call for the development of a novel Sustainable Construction Living Lab (SCLL) model as a new user-centric environment integrating open and sustainable innovation principles as the foundations of an ongoing ITESM-CEMEX collaborative research project. This SCLL to be developed, also aims to incorporate the key construction stakeholders in activities such as testing, validating, realizing and/or refining the next generation construction innovations to be tested in real life environments as part of collaborative sustainable construction projects. Besides stakeholders in construction sector, other actors in the innovation system, such as Government Environmental Auditors, Non-Governmental Organisations (NGOs) and Universities will also be integrated to increase users' and citizens' awareness to invest in sustainable solutions.

\section{Towards a Sustainable Construction Living Lab Model}

The construction industry has always been an intra- and inter- collaborative sector, since in order to erect structures and buildings a great number of intra-stakeholders like architects, designers, engineers, builders, craftsmen and machine operators, and inter-stakeholders such as hardware suppliers (e.g. steel, concrete, wood, etc.) and software providers (e.g. computers, ICT tools) have to get involved and work together in a construction project. But, one key current challenge in the construction industry is to achieve collaborative sustainable construction projects driven by the users innovation needs. Thus, this challenge requires a stronger collaboration between the key construction stakeholders, a new mindset regarding sustainable construction and putting the building owners and users at the center of the sustainable innovation process.

In order to face this challenge, $\mathrm{CEMEX}^{1} \& \mathrm{ITESM}^{2}$ have joined forces to collaborate in an applied research project to design, validate and deploy a SCLL model to integrate key construction stakeholders and end-users to collaboratively propose and develop the next generation construction innovations for sustainable building solutions. The project will also apply a Sustainable Innovation Framework [Flores et al, 2009] as a guideline to embed four key enablers to achieve the expected results: (1) mass-customization, (2) sustainable development, (3) value network <management> and (4) product/service lifecycle.

Main research questions leading this initiative are:

- How can a SCLL provide new sustainable solutions to issues raised today in the construction industry and tackle economical, social and environmental opportunities?

- Which are the business and governance models that will facilitate key users and players to collaborate in the SCLL?

For instance, help to raise awareness on ecological business opportunities and issues in the industry or encourage collaborative, sustainable and innovative building solutions between key construction stakeholders and future building owners and users. Main research methodologies will be study cases for the $S C L L$ development and action-research to propose and develop the next generation collaborative solutions.

\footnotetext{
1 CEMEX is a growing global building solutions company that provides consistent quality products and reliable services to its customers: www.cemex.com

${ }^{2}$ ITESM is a Mexican University that has identified research and technological development as vital elements for sustainable development: www.ccm.itesm.mx
} 


\subsection{The Sustainable Construction Living Lab Origin, Definition and Benefits}

The proposal of creating a $S C L L$ can be seen as an extension of the Living $L a b(L L)$ original idea developed by Professor William J. Mitchell from MIT by means of putting key construction stakeholders to co-develop building solutions together in collaboration with the future building owners and users, and as a contribution to the World Green Agenda. This last concern was raised because the environmental impact of the construction industry accounts for a relevant percent (\%) regarding energy use, natural resources consumption, greenhouse gas emissions, airborne particulate production and landfill waste generation. Therefore, authors' belief a SCLL model can make a big difference in the journey for achieving a more sustainable construction industry and achieving synergies and thus, multiplying effects in the sector.

\subsubsection{The Construction Living Lab Origin}

According to Annerstedt \& Haselmayer [2006], the $1^{\text {st }}$ Generation Construction Living Labs were created by architects and engineers interested in co-developing with future residents in already existing building to be better adapted to new users' needs. Here, users were invited to co-design an apartment or other living quarters during the final stages of the construction period. As a result, new methodologies for participatory design processes were developed.

Furthermore, based-on the Three Living Lab Generations proposed by Annerstedt \& Haselmayer [2006], nowadays the construction sector living labs may be placed in an early stage of the $2^{\text {nd }}$ Generation where key construction stakeholders are getting involved in shaping new user-centric environments and collaborative innovation networks supported by state-of-the-art construction collaboration technologies. At this point, a lot of work remains to be done in order to develop proper reference models, methods and tools to create and manage genuine construction living labs with their interactive working environments where key stakeholders can participate in innovation processes together with the future building owners and users, sharing their collective core-competencies, experiences and resources to jointly deliver the best solution that meets the user requirements and construction regulations [Wilkinson, 2005].

Finally, the $3^{\text {rd }}$ Generation could be foreseen as envisioning full-scale urban laboratories where all society stakeholders including local governments, community, construction enterprises and building owners will be planning, testing and developing new orders and designs for sustainable settlements (e.g. residentional zones, office buildings, industrial parks, transportation infrastructure, etc.) to achieve a better quality of living in a city or region (e.g. the new urbanism).

\subsubsection{The Sustainable Construction Living Lab Definition}

This paper will focus its contributions to the $2^{\text {nd }}$ Generation Construction Living Labs and will add the elements of sustainable construction and sustainable innovation as differentiators to the other existing construction living lab models.

Sustainable Construction means designing and delivering sustainable solutions that are easily reproducible and that integrate robust strategies for lean construction and building maintenance across structures lifecycle. For example: planning for land reuse and materials recycling; designing for minimum waste and energy consumption, natural resources conservation and environmental impact near zero; building controlling resources efficient utilization, air pollution and taking advantage of local procurement to reduce energy use related to staff and materials transportation; using intelligent systems like sensors to reduce water and energy consumption; and maintaining the structure in efficient operation till its required to plan a renewing project to comply with new user-needs or a recycling project for the construction materials after the structure demolition.

In the other hand, Sustainable Innovation means taking care of economic, social and environmental aspects when developing new construction materials and/or lean construction techniques. For example: off-site construction resulting in new job creation and business 
opportunities for local suppliers and service providers (economic aspect); modular components that make faster the construction process reducing the disturbance-time in the surrounding to the construction site (social aspect); or efficient building design and management reducing the structure ecological footprint (environmental aspect).

Combining these two elements, a Sustainable Construction Living Lab (SCLL) can be defined as "an open community of building owners and users, and associated enterprises to the construction sector experimenting and co-creating in real life environments new robust and sustainable solutions for planning, constructing and maintaining intelligent buildings; always considering the economic, social and environmental aspects of sustainable development in the whole innovation process and the structures lifecycle". In the SCLL, the building owners and users are the main driver of the innovative ideas.

Major theories contributing the SCLL concept are (1) the user-driven innovation theory by von Hippel [2005], (2) the open innovation theory by Chesbrough [2006] and (3) the sustainable innovation theory represented in this case by Charter \& Clark [2007]. The first author's contribution changes the customer role to an active partner in the value-creation/innovation process, while the second author opens the spectrum of innovation sources beyond the R\&D department boundaries, and at the same time the third authors introduce sustainability considerations to the innovation process from the idea generation, through $\mathrm{R} \& \mathrm{D}$ to the commercialization.

Thus, the main purpose of the proposed SCLL to be developed by this ITESM-CEMEX collaborative research project, is to bring together the ideas and prototypes of the key construction stakeholders into an open innovation and user-centric environment, supported by a high-tech platform, offering the needed working principles, methods and tools to provide improved insights into the next generation construction innovations (e.g. products, services, processes, business models, etc.) in order to satisfy the market demands in a sustainable way.

\subsubsection{The Sustainable Construction Living Lab Benefits}

From a collaborative networked perspective, a living lab can be understood as a type of collaborative innovation network offering intuitive collaboration advantages to its members. Therefore, in order to promote the adoption of a SCLL model by the key construction stakeholders it is important to identify and characterize some of these collaboration benefits [adapted from Camarinha-Matos \& Abrue, 2004], for instance: (1) share costs in R\&D, (2) share risk in collaborative sustainable construction projects (e.g. co-responsibility), (3) decrease dependency with construction stakeholders by creating privileged links within the construction value network (e.g. the integrated enterprise), (4) increase innovation capacity by generating new ideas together with the users through the combination of experiences, (5) increase flexibility by sharing resources and skills to offer a broader rage of sustainable construction solutions, (6) increase agility to react to construction projects opportunities by working in collaboration, (7) increase specialization by letting key construction stakeholders concentrate on their core-competencies on critical activities.

Other benefits identified regarding the adoption of a SCLL model from a sustainable development perspective are [adapted from the Sustainable Construction Network, http://www.the-sbp.co.uk/]: (1) public relations power with those ecological users leading to more users-involvement in the SCLL (e.g. word-of-mouth marketing), (2) differentiation to other construction businesses by promoting sustainable solutions, (3) better construction solutions according to the true user-needs by stimulating teamwork between key construction stakeholders and building owners and users, (4) novel sustainable construction solutions that may be a little bit expensive but based-on the water and energy saving provided for example, they pay their-selves over a certain period of time.

In general the benefits of adopting a SCLL model will be creating buildings and structures that humans enjoy and feel proud about, since these infrastructures stand for a sustainable development vision for a better quality of living... for a better World for future generations. 


\subsection{Mapping the Key Members for the Sustainable Construction Living Lab}

Till now, much has been said about the key construction stakeholders, but who are they and which are their innovation needs and opportunities? Table 1 introduces a typology based-on several of the key construction actors proposed by the BUILDNOVA [2006] project who can be considered important members of the TO-BE SCLL under development by this ITESM-CEMEX collaborative research project.

Table 1: Proposed SCLL Members \& their Innovation Needs and Opportunities [adapted from BUILDNOVA, 2006]

\begin{tabular}{|c|c|c|}
\hline $\begin{array}{c}\text { SCLL } \\
\text { (Members) }\end{array}$ & $\begin{array}{l}\text { Key Construction Stakeholders } \\
\text { (Description) }\end{array}$ & $\begin{array}{l}\text { Innovation Needs and Opportunities } \\
\text { (Examples) }\end{array}$ \\
\hline \multicolumn{3}{|c|}{ Construction Value-Chain } \\
\hline $\begin{array}{l}\text { Building } \\
\text { Owner }\end{array}$ & $\begin{array}{l}\text { The one who generally pays for } \\
\text { the building design and construction. }\end{array}$ & $\begin{array}{l}\text { Collaboration with the service providers to improve the availability and } \\
\text { accessibility of construction services (e.g. maintenance, renewal), reduce energy } \\
\text { costs, implement novel water management systems, integrate new long lasting } \\
\text { materials, etc. }\end{array}$ \\
\hline $\begin{array}{l}\text { Building } \\
\text { User(s) }\end{array}$ & Designates people who use the building. & $\begin{array}{l}\text { Human science principles are hardly presented in current construction industry } \\
\text { where building users involvement in the structures design and indoor } \\
\text { environments is one of the most important arenas for innovation opportunities. }\end{array}$ \\
\hline $\begin{array}{l}\text { Designer } \\
\text { or } \\
\text { Architect }\end{array}$ & Architectural design professionals. & $\begin{array}{l}\text { Innovative design criteria should be elaborated in close cooperation with } \\
\text { building users and society requirements. The designer role is critical, as } \\
\text { the designer in most of the cases selects the materials and technologies } \\
\text { to be used in the construction. }\end{array}$ \\
\hline Contractor & Firm specialized in building construction. & $\begin{array}{l}\text { Most important innovation opportunities can be found in new construction } \\
\text { techniques and services, for example: innovative techniques to eliminate waste } \\
\text { within the whole construction lifecycle or automation of construction systems } \\
\text { to replace human labour in hazardous conditions, or innovative services such as } \\
\text { alternative solutions for technical building service systems or integrated } \\
\text { maintenance services for the whole building lifecycle. }\end{array}$ \\
\hline $\begin{array}{l}\text { Products } \\
\text { Manufacturer }\end{array}$ & $\begin{array}{l}\text { Firm that produces any part, material or } \\
\text { component needed for the building. }\end{array}$ & $\begin{array}{l}\text { Major innovation opportunities can be found in novel products and processes, } \\
\text { for example: ICT applications to record construction systems and structures } \\
\text { performance in-use, improved materials in durability which required less } \\
\text { maintenance, or eco-friendly construction processes and products with less } \\
\text { environmental impact. }\end{array}$ \\
\hline $\begin{array}{l}\text { Products } \\
\text { Distributor }\end{array}$ & $\begin{array}{l}\text { Intermediary between product } \\
\text { manufacturers and contractors. }\end{array}$ & $\begin{array}{l}\text { Key innovation opportunities can be found in e-commerce and information } \\
\text { sharing between construction stakeholders, for example: improving } \\
\text { communication systems or promoting sustainable devices and products. }\end{array}$ \\
\hline $\begin{array}{l}\text { Material } \\
\text { Supplier }\end{array}$ & $\begin{array}{l}\text { Firm that provides the necessary material } \\
\text { for the building products production. }\end{array}$ & $\begin{array}{l}\text { Main innovation opportunities are in products, for example: new eco-friendly, } \\
\text { durable and light-weight materials. }\end{array}$ \\
\hline $\begin{array}{l}\text { Service } \\
\text { Provider }\end{array}$ & $\begin{array}{l}\text { Firm that takes (totally or partially) } \\
\text { in charge of the maintenance of } \\
\text { the building and the wastes generated } \\
\text { during its complete life cycle. }\end{array}$ & $\begin{array}{l}\text { The relevant innovation opportunities can be found in new services, for example: } \\
\text { novel services catalogues, contract models, new business models, open-methods } \\
\text { for information management between parties, simulator based-solutions for } \\
\text { training purposes, modern tools to speed-up product development and testing. }\end{array}$ \\
\hline $\begin{array}{l}\text { Technology } \\
\text { Infrastructure } \\
\text { Providers }\end{array}$ & $\begin{array}{l}\text { Firms that bring information technologies } \\
\text { support to the construction projects. }\end{array}$ & $\begin{array}{l}\text { Relevant innovation opportunities can be found in new information technologies } \\
\text { like mobile technology and handheld devices offering an easy way of collecting } \\
\text { data or spreading information to the workers in the construction site. }\end{array}$ \\
\hline Neighbours & $\begin{array}{l}\text { The ones who are generally affected or } \\
\text { benefit with a new construction project. }\end{array}$ & $\begin{array}{l}\text { Innovative initiatives for good neighbourhood, encouraging neighbours and } \\
\text { construction stakeholders to communicate with each other about planned } \\
\text { building activities to increase cooperation and understanding. }\end{array}$ \\
\hline \multicolumn{3}{|c|}{ Other Key Members to be considered in the Sustainable Construction Living Lab to be developed... } \\
\hline $\begin{array}{l}\text { Government } \\
\text { Auditor }\end{array}$ & $\begin{array}{l}\text { A public agent in charge of assessing } \\
\text { the compliance of local policies and } \\
\text { regulations in the construction industry. }\end{array}$ & $\begin{array}{l}\text { Compliance should be achieved when government auditors assess regulations } \\
\text { are followed successfully. }\end{array}$ \\
\hline NGOs & $\begin{array}{l}\text { Non-Governmental Organizations are } \\
\text { part of the value chain to increase } \\
\text { the awareness in the final users. }\end{array}$ & $\begin{array}{l}\text { To integrate new sustainable solutions NGOs can increase awareness among } \\
\text { users. }\end{array}$ \\
\hline Universities & $\begin{array}{l}\text { Universities can act as coachers } \\
\text { to develop new solutions together with } \\
\text { the industry and increase awareness in } \\
\text { its citizens to invest in new solutions } \\
\text { to integrate in their houses, offices, etc. }\end{array}$ & $\begin{array}{l}\text { Universities can spur the innovation cycle by collaboratively develop } \\
\text { innovations with enterprises. Additionally, as NGOs can increase citizen } \\
\text { awareness by developing new courses and diffusion of opportunities to the local } \\
\text { communities. }\end{array}$ \\
\hline
\end{tabular}




\subsection{The Sustainable Construction Living Lab Lifecycles Management}

A SCLL represents a big management challenge regarding three different lifecycles that have to be managed simultaneously. The first one is the innovation lifecycle composed by four stages: (1) ideation - were construction stakeholders and building owners and users engage in an active dialogue for listening what the end-users need in order to define a "research agenda" towards the next generation construction innovations, (2) ongoing research - were construction stakeholders and end-users continuously work together under a user-driven approach to design and test new innovation concepts, (3) prototyping - were trial products, services and/or processes are placed in the hands of their end-users to observe and gain feedback on how their designs and features can be improved, and (4) deploying - were new innovative and sustainable construction solutions are released to be used in construction projects. Second one is the construction project lifecycle with four stages: (1) conceptualization - were different construction materials and techniques are evaluated to select the ones that save more energy, water and waste during the construction development, (2) project planning - were the latest available sustainable construction materials and techniques are maximized with the local sourcing available to support local economies and minimize energy use in transportation and travelling, (3) project execution - were best practices for controlling resources utilization and pollution are deployed during the construction process, and (4) project deliver - were recommendations for the building maintenance are provided to the building owner(s). And third one is the building <it-self> lifecycle integrated by six stages: (1) planning - to leave the smallest environmental footprint as possible, (2) designing - to minimize energy and water consumption and greenhouse gas emissions, (3) building - with a minimum of waste in its construction, (4) using - making proper use of energy and water resources thanks to efficient light, ventilation, air conditioning and rainfall systems, (5) maintaining - to avoid water wastes because of plumbing problems and/or energy wastes because of power, heating and/or air condition problems, and (6) renewing or recycling - always trying to refurbish the building for the new user-needs and leaving the demolition choice as the last option, but if that is the case always trying to recycle as much as possible the construction materials.

It is important to mention that the innovation lifecycle "outputs" will be used as "inputs" by the construction project and building lifecycles in order to apply state-of-the-art construction materials, systems and techniques to achieve sustainable and innovative buildings and structures.

\subsection{The Sustainable Construction Living Lab Innovation Framework}

In a $S C L L$, the proposal for sustainable innovation management is focused on developing new or improved resource-efficient strategies to implement new ideas while maximizing value for the construction stakeholders and building owners and end-users. It involves harnessing the creative and innovative ideas of individuals and organisations and utilizing it to bring the new innovations to the market in sustainable way. Therefore, a Sustainable Innovation Living Lab Framework [adapted from Flores et al, 2009] integrates four key enablers "or strategies" to be offered to the SCLL members in order to support the achievement of the expected innovative and sustainable results: (1) mass-customization - relates to the ability to provide customized construction solutions through flexible and resource-efficient processes by delivering what the building owners and end-users want (e.g. user-driven design) and improving construction stakeholders resources consumption through reducing energy and materials wastes as a result of offering products and services just when they are needed (e.g. ad-hoc production/offering); (2) sustainable development - targets a new mindset for the construction stakeholders and building owners and users, were existing and emerging sustainable development best practices are continuously incorporated to the construction industry daily business operations and to the building users daily lifestyle, covering the entire innovation, construction projects and buildings lifecycles; (3) value network <management> - considers strategic alliances to operate under a collaborative networks paradigm aimed to harness the SCLL members' core-competencies byorchestrating business networks that generated added value for building owners and users; and 
(4) product/service lifecycle - thinks in a paradigm shift which implies new construction materials and processes/services that have been designed to produce a low environmental impact and to be recycling.

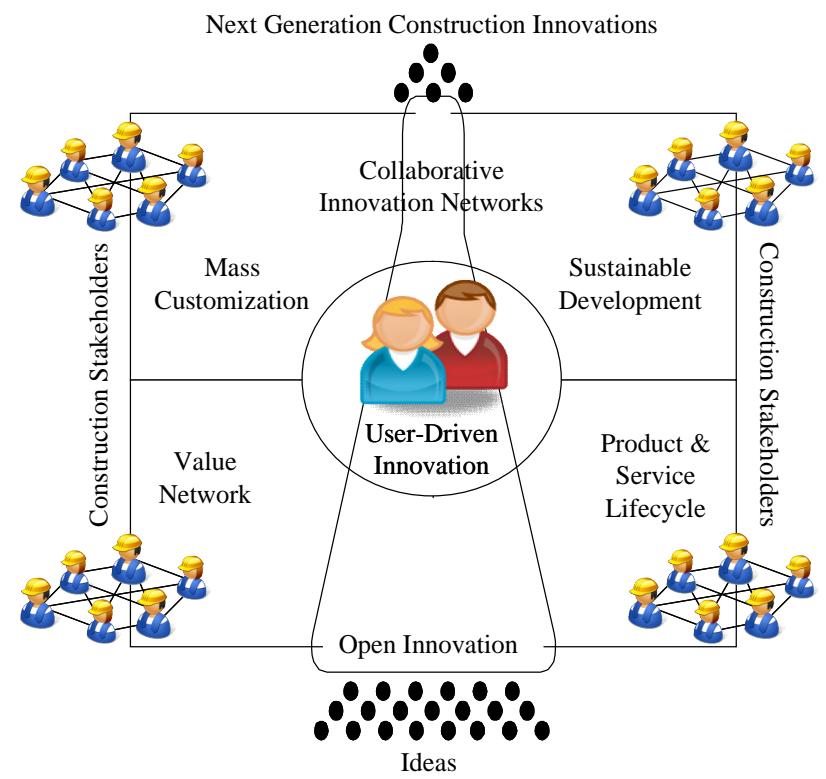

Figure 1: Proposed Integrated Sustainable Construction Living Lab Model and Innovation Framework

\section{Sustainable Construction Living Lab: Key Components, Features \& Principles}

Using the six topics proposed in the Living Labs Harmonization Cube [see Mulder et al, 2007; 2008], the following toolkit (e.g. models, methods and tools) is foreseen by a SCLL:

\subsection{User Involvement}

The most flourishing innovation paradigms nowadays recognize the importance of involving users in the entire innovation lifecycle. User involvement appears to be an interesting approach to guide researchers towards products, processes and services that are innovative and appreciated by the end-users. This strategy implies involving users in the ideation, design, development, delivery and dissemination of the innovation outcomes. Therefore, some available best practices for this purpose can be borrowed from available studies regarding (online) customer communities where a lot of progress has been made already about how customer communities can be created and managed for innovation purposes [see Tzu-Ying \& Jen-Fan, 2004].

At the present time, in the construction industry, future building owners are the only ones that are commonly considered during the ideation and design processes of a building; nevertheless the challenge is to involve also the future building users in these processes and then complete both actors involvement in the entire construction project and building lifecycles.

\subsection{Service Creation}

Service providers play a fundamental role as suppliers of testbed and experimental platforms where users can get involved in innovation processes to design, test, prototype and confront new and enhanced products/services with usage situations, and provide feedback loops to the designers to enhance these prototypes and/or renewed products/services that are being shape in real life contexts [Ballon et al, 2005].

Some key services required to support a SCLL may include [Zarli et al, 2007]: methods and tools for capturing building owners and users' requirements for construction projects, applications to customize construction solutions (e.g. products, processes and services), methods for off-site production, ICT tools for e-procurement and logistics management, rapid on-site assembly methods using intelligent equipment, new materials and modular manufactured components, etc. 


\subsection{Infrastructure}

ICT-infrastructures represent an important enabler for interoperation and cooperation among collaborative entities such as individuals (e.g. end-users) and organisations (e.g. stakeholders).

ICT-infrastructures as real collaborative platforms are much more than CSCW environments enabling the execution of groupware facilities, they are complex ICT architectures providing collaborative ICT tools for ideas management, information sharing, decision support, team composition, project steering, risk management and on-site monitoring to mention some in the context of the construction industry [Zarli et al, 2007; Stokic, 2007].

\subsection{Governance}

Under a strategic level, governance refers to the use of democratic structures of authority to allocate resources and coordinate or control activities in a living lab, while under an operation level, governance means setting the framework within all living lab members will make decisions, negotiations and accommodations between parties involved and taking actions to optimize the living lab functionalities, relationships and performance [adapted from Romero et al, 2007].

\subsection{Innovation Outcomes}

"The outcome of a successful innovation will always depend on the input provided at the beginning of the innovation process... the idea". Main enablers for promoting the submission of good ideas and therefore enhancing the living lab innovation outcomes will be related to offering the ideas providers their corresponding intellectual property rights and benefits over the innovation exploitation.

\subsection{Methods \& Tools}

The integration of users and stakeholders into a collaborative innovation process in a living lab will require different methods and tools according to the living lab domain, some generic methods used in exiting living labs covering the whole product innovation lifecycle may be found in Schumacher \& Feurstain [2007]. Still specific methods and tools have to be developed for the construction industry, but Schumacher \& Feurstain [2007] provide a good starting point.

\section{Future Scenario, Conclusions \& Further Research}

A future scenario for sustainable buildings can be depicted in Fig. 2, where key construction stakeholders and building owners and users involved in a SCLL integrate innovative materials, designs, techniques and technologies to achieve innovative and sustainable structures.
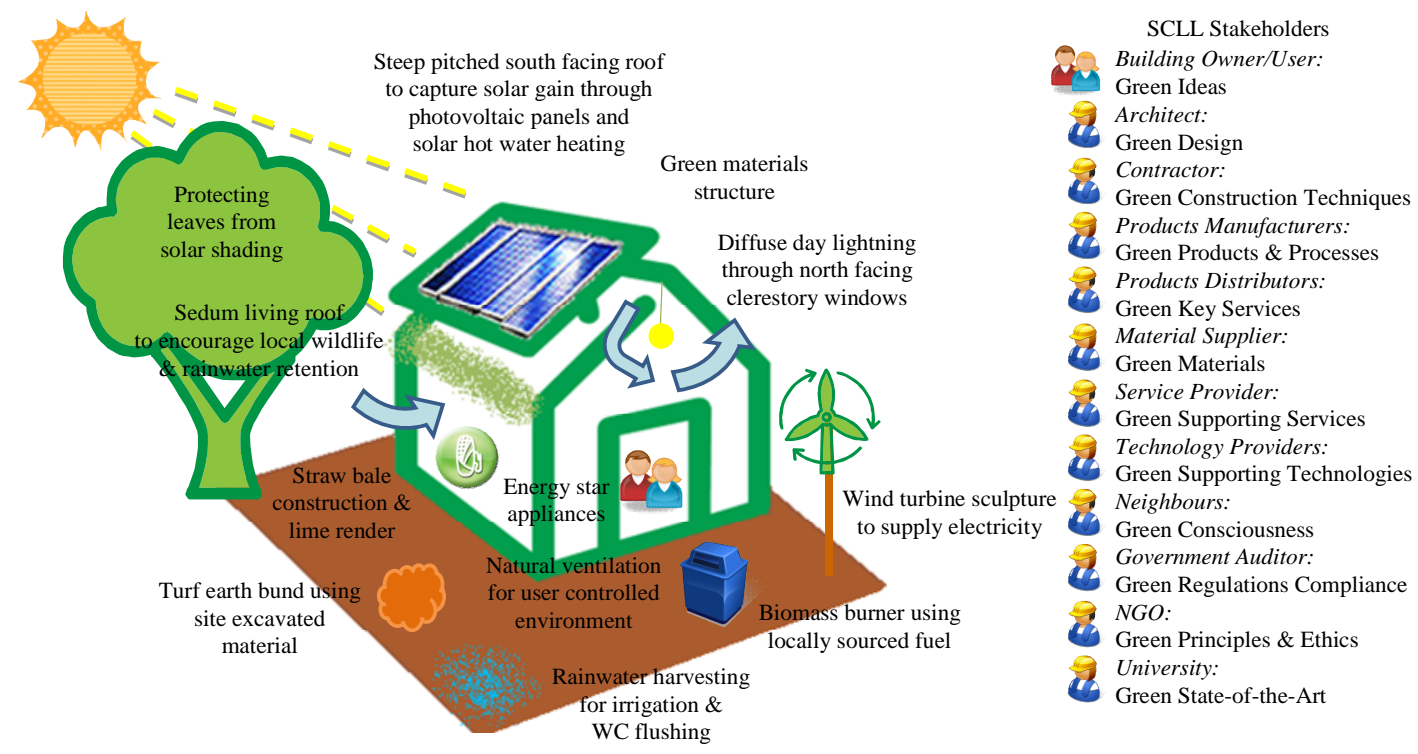

Figure 2: Sustainable Solutions [based-on Sustainable Construction Network, URL] 
This paper introduces a general overview on the objectives and expected results of a collaborative research project by CEMEX \& ITESM in order to create a Sustainable Construction Living Lab model and its Sustainable Innovation Framework as a formal initiative to promote and support innovative and sustainable solutions in the construction industry. A lot of work remains to be done, since the project is currently starting, nevertheless it is clear that in theory and practice new sustainable development strategies are required in the construction industry to reduce its negative impact in the environmental, that user involvement is a must in the new innovation paradigms, and that collaboration between key construction stakeholders is required to deliver innovative and sustainable construction solutions.

\section{Acknowledgement}

The research presented in this document is a contribution for the "Rapid Product Realization for Developing Markets Using Emerging Technologies" Research Chair, ITESM, Campus Monterrey, and for the "Technological Innovation" Research Chair, ITESM, Campus Mexico City. This work was possible in part by a collaborative funded research project by CEMEX Research Group AG and ITESM University.

\section{References}

Annerstedt, J. and Haselmayer, S. (2006). "Third Generation Living Labs: The Quest for User-Centered Mobile Services", eChallenges Proceedings 2006.

Ballon, P.; Pierson, J., and Delaere, S. (2005). "Test and Experimentation Platforms For Broadband Innovation: Examining European Practice", 16th European Regional Conference, International Telecommunications Society.

BUILDNOVA (2006). "Characteristics of the construction sector - technology and market tendencies", Building Innovation in the European Construction Sector.

Charter, M. and Clark, T. (2007). "Sustainable Innovation: Key Conclusions from Sustainable Innovation Conferences 2003-2006", The Centre for Sustainable Design University College for the Creative Arts.

Chesbrough, H. (2006). "Open Innovation: The New Imperative for Creating and Profiting from Technology" (Book), Harvard Business Press, ISBN-10: 1422102831, ISBN-13: 9781422102831.

Flores, M.; Canetta, L.; Castrovinci, A.; Pedrazzoli, P.; Longhi, R. and Boër, C.R. (2009). “Towards an Integrated Framework for Sustainable Innovation", to appear in the International Journal of Sustainable Engineering.

Marcela Miozzo, M and Dewick, P. (2004). "Innovation in Construction: A European Analysis" (Book), Edward Elgar Publishing, ISBN-10: 1843765217, ISBN-13: 978-1843765219.

Mulder, I.; Fahy, C.; Hribernik, K.; et al (2007). "Towards Harmonized Methods and Tools for Living Labs", Expanding the Knowledge Economy: Issues, Applications, Case Studies, pp. 722-729, IOP Press.

Mulder, I.; Velthausz, D. and Kriens, M. (2008). "Living Methodologies: Understanding the Dynamics of Innovation”, EU Living Labs: A New Approach for Human Centric Regional Innovation, pp. 31-38.

Paevere, P. \& MacKenzie, C. (2007). "Emerging Technologies and Timber Products in Construction - Literature Review", Market Knowledge \& Development, Project Number: PN05.1022, Australian Government, Forest and Wood Products Research \& Development Corporation.

Romero, D.; Giraldo, J.; Galeano, N. and Molina, A. (2007). “Towards Governance Rules and Bylaws for Virtual Breeding Environments", Establishing the Foundation of Collaborative Networks, Springer Publisher, pp. 93-102.

Schumacher, J. and Feurstain, K (2007). "Living Labs - the User as co-creator", 13th International Conference on Concurrent Enterprising, pp. 27-32.

Stokic, D (2007). "Collaborative Working Environment for Innovation in Manufacturing Industry", 13th International Conference on Concurrent Enterprising, pp. 67-76.

Sustainable Construction Network, URL: http://www.the-sbp.co.uk/

Tzu-Ying, C. and Jen-Fan, L. (2004). "A Comparative Study of Online User Communities Involvement in Product Innovation and Development", 13th International Conference on Management of Technology.

von Hippel, E. (2005). "Democratizing Innovation" (Book), MIT Press, ISBN-10: 0262002744.

Wilkinson, P. (2005). "Construction Collaboration Technologies: The Extranet Evolution" (Book), Taylor \& Francis, ISBN-10: 0415358590, IBSN-13: 9780415358590.

World Business Council for Sustainable Development, URL: http://www.wbcsd.org/

Zarli, A.; Samad, Abdul; Hannus, M. and Bourdeau, M. (2007). "Start-CON: A Strategic Vision for Future R\&D and Innovation in the ICT-enhanced Construction", 13th Inter. Conference on Concurrent Enterprising, pp. 67-76. 